\title{
PENGARUH VARIASI WAKTU DAN REDUKTOR PADA PELEBURAN TITANIUM DARI TERAK TIMAH MENGGUNAKAN TUNGKU BUSUR LISTRIK
}

\author{
Effect of Time and Reductant Ratio on Titanium Smelting Process \\ from Tin Slag Using Electric Arc Furnace
}

\author{
YAYAT I. SUPRIYATNA ${ }^{1}$, BENING N. H. KAMBUNA ${ }^{2}$, KURNIA TRINOPIAWAN ${ }^{3}$ dan \\ PANGGI A. PUTRA ${ }^{4}$ \\ ${ }^{1}$ Balai Penelitian Teknologi Mineral (BPTM) - LIPI \\ Jalan Ir. Sutami Km. 15 Tanjung Bintang, Lampung Selatan, 35361 \\ e-mail :yayatiman@yahoo.com \\ 2 Teknik Metalurgi - Universitas Sultan Ageng Tirtayasa \\ Jalan Raya Jkt Km 4, Panancangan, Kec. Cipocok Jaya, Kota Serang, Banten 42124 \\ ${ }^{3}$ Pusat Teknologi Bahan Galian Nuklir (PTBGN) - BATAN \\ Jl. Lebak Bulus Raya No.9, RT.3/RW.2, Lebak Bulus, Cilandak, Jakarta Selatan \\ 4 Teknik Mesin - Universitas Muhamadiyah Metro \\ Iringmulyo, Kec. Metro Timur, Kota Metro, Lampung 34381
}

\begin{abstract}
ABSTRAK
Pengolahan bijih timah menjadi logam timah akan menghasilkan limbah berupa terak. Metode pirometalurgi biasanya dipilih dalam mengolah bijih timah tersebut karena mempunyai kelebihan, yaitu prosesnya lebih singkat dan dapat menghasilkan logam lebih murni. Salah satu proses pirometalurgi adalah menggunakan alat tungku busur listrik. Tungku busur listrik merupakan salah satu alat yang berperan dalam proses reduksi dan peleburan mineral Ilogam. Tungku busur listrik satu fasa memiliki beberapa kelebihan dalam penggunaannya, di antaranya konsumsi penggunaan elektroda dan konsumsi energi yang rendah. Pada penelitian ini dilakukan ekstraksi titanium menggunakan tungku busur listrik dengan variasi waktu proses dan rasio reduktor untuk mereduksi dan melebur terak timah. Waktu proses yang digunakan 20, 30, 40, 50 dan 60 menit serta variasi reduktor yaitu 1:5, 1:7 1:10, 1:13, dan 1:15 dengan temperatur peleburan yang sama yaitu $1600^{\circ} \mathrm{C}$. Kadar titanium tertinggi diperoleh pada waktu proses 30 menit yaitu sebesar 23,11\% pada rasio reduktor 1:15 dengan persen ekstraksi titanium sebesar 79,21\%.
\end{abstract}

Kata kunci : ekstraksi titanium, reduktor, terak timah, tungku busur listrik, waktu proses.

\begin{abstract}
Processing the tin ore will produce a tin slag waste. The pyrometallurgical method used in this process has an advantage, namely, shorter process and producing pure metals. One of the pyrometallurgical processes is using the electric arc furnace. Such a furnace is one of the tools that has a role in smelting process and metal mineral reduction. Its advantages include low electrode and low energy consumptions. In this study, titanium extraction was carried out using an electric arc furnace with variations in smelting time and reducing ratio. Smelting was conducted in an electric arc furnace by varying smelting time for 20,30, 40, 50 and 60 minutes. The process was also carried out at a temperature of $1600^{\circ} \mathrm{C}$ and varied the reducing agents from 1:5, 1:7 1:10, 1:13, and
\end{abstract}


1:15. The highest titanium content was achieved at 30 minutes, namely $23.11 \%$ at redactor ratio of 1:15 and percent titanium extraction of $79.21 \%$.

Keywords: electric arc furnace, tin slag, reducing agent, titanium extraction, smelting time.

\section{PENDAHULUAN}

Titanium merupakan unsur terbanyak kesembilan dalam kerak bumi dan tersebar secara luas. Logam ini memiliki sifat tahan korosi, tahan terhadap suhu tinggi dan memiliki afinitas besar terhadap oksigen, nitrogen dan unsur lain. Karena itu titanium tidak terdapat dalam bentuk logam stabil di alam, tapi dalam bentuk mineral yang stabil (Gambogi, 2006). Titanium banyak diaplikasikan dalam berbagai bidang, seperti pelapis, adsorben, kosmetik, katalis, sensor gas, stabilitas panas dan lain sebagainya (Xue $d k k ., \quad 2009)$. Beberapa metode yang digunakan untuk mengekstraksi titanium yaitu metode hidrometalurgi, pirometalurgi, dan elektrometalurgi.

Indonesia merupakan negara kedua yang memiliki cadangan timah terbesar setelah Malaysia yakni sekitar 800.000 ton (Yuliana, 2017). Pengolahan bijih timah akan menghasilkan limbah berupa terak timah. Terak dihasilkan dari proses reduksi bijih timah dalam tanur peleburan bijih timah, sehingga diperoleh produk timah cair dan terak. Terak ini masih mengandung banyak mineral seperti $\mathrm{SnO}_{2}, \mathrm{CaO}, \mathrm{Fe}_{2} \mathrm{O}_{3}, \mathrm{SiO}_{2}, \mathrm{TiO}_{2}$, $\mathrm{ZrO}, \mathrm{Al}_{2} \mathrm{O}_{3}, \mathrm{CeO}_{2}, \mathrm{La}_{2} \mathrm{O}_{3}, \mathrm{Nd}_{2} \mathrm{O}_{3}, \mathrm{Y}_{2} \mathrm{O}_{3}$, $\mathrm{Nb}_{2} \mathrm{O}_{5}$, dan $\mathrm{WO}_{3}$ (Sulistiyono, Firdiyono dan Suharyanto, 2014).

Terak timah banyak tertimbun dan cenderung menjadi limbah karena pemanfaatannya masih relatif kecil dan belum maksimal (Mareta, 2011). Oleh karena itu, pihak perusahaan menyediakan lokasi khusus untuk menampung limbah ini dan mendirikan tembok tinggi dengan ketebalan yang telah ditentukan. Apabila limbah terak timah tersebut dibiarkan terus menerus akan bertambah banyak dan bisa membahayakan tenaga kerja yang beraktivitas di lingkungan tersebut. Hal ini dikarenakan terak mengandung zat radioaktif. Di samping itu, pemanfaatan terak tersebut masih sangat terbatas yaitu sebagai agregat halus campuran beton (Melita, 2015) sedangkan terak timah masih mengandung titanium oksida $\left(\mathrm{TiO}_{2}\right)$ sebesar 11,92 \% (Permana dkk., 2016), sehingga diperlukan pemanfaatan lebih lanjut untuk mengekstrak titanium dari limbah ini.

Xue dkk. (2009) telah melakukan ekstraksi titanium menggunakan metode hidrometalurgi dengan bahan baku terak titanium dan variasi ukuran partikel 75-125, 58-75, dan 48-58 $\mu \mathrm{m}$, rasio massa $\mathrm{NaOH}$ terhadap terak $1,2: 1 ; 1,5: 1$; dan $1,8: 1$, serta variasi suhu tanur $400-475^{\circ} \mathrm{C}$. Hasil yang diperoleh, ekstraksi titanium meningkat seiring dengan menurunnya ukuran partikel, pengaruh rasio massa $\mathrm{NaOH}$ terhadap terak pada ekstraksi titanium 1,5: 1 dengan ekstraksi titanium sebesar $94 \%$ bisa tercapai, dan ekstraksi meningkat seiring dengan meningkatnya suhu reaksi. Nie $d k k$. (2006) melakukan ekstraksi titanium menggunakan metode elektrolisis dengan larutan garam $\mathrm{CaCl}_{2}$ serta variasi suhu $850-900^{\circ} \mathrm{C}$ dan potensi elektrolisis 3,1 dan 3,2 V, menghasilkan titanium dengan kemurnian tinggi. Ekstraksi titanium menggunakan metode hidrometalurgi dan pirometalurgi dengan bahan baku terak titanium telah dilakukan oleh Middlemas, Fang dan Fan (2013) menggunakan variasi waktu panggang, konsentrasi $\mathrm{HCl}$ dan suhu tanur Hasil yang didapat yaitu ekstraksi titanium meningkat seiring dengan penambahan konsentrasi $\mathrm{HCl}$ dan meningkatnya suhu. Ekstraksi titanium yang keseluruhan prosesnya menggunakan metode pirometalurgi masih jarang dilakukan. Metode ini mempunyai kelebihan yaitu prosesnya lebih singkat dan menghasilkan logam lebih murni. Salah satu proses pirometalurgi adalah menggunakan alat tungku busur listrik (Supriyatna dan Shofie, 2013).

Tungku busur listrik merupakan salah satu alat yang berperan dalam proses peleburan dan reduksi mineral logam. Tungku busur listrik satu fasa atau DC tungku busur listrik memiliki beberapa kelebihan dalam penggunaannya, di antaranya konsumsi penggunaan elektroda dan energi rendah (Tangstad dan Olsen, 1995).

Reduktor merupakan bahan yang digunakan untuk mereduksi oksida logam menjadi logam murni. Bahan ini banyak mengandung unsur karbon (C) dan material yang biasanya 
digunakan adalah kokas dan batubara. Pada penelitian ini reduktor yang digunakan adalah grafit karena grafit memiliki karakteristik yang menarik yaitu susunan atom karbonnya sangat teratur dan hampir sempurna.

Mengacu kepada latar belakang di atas, pada penelitian ini dilakukan proses ekstraksi titanium dari terak timah menggunakan tungku busur listrik dengan variasi waktu proses dan rasio reduktor grafit untuk mendapatkan ekstraksi titanium yang tinggi.

\section{METODE}

Terak timah yang digunakan pada penelitian ini berasal dari PTBGN-BATAN. Bahan lain yaitu grafit dan kapur. Grafit merupakan reduktor yang menjadi sumber karbon dalam reduksi dan peleburan terak timah. Kapur digunakan untuk mengikat pengotor saat peleburan. Pada penelitian ini, kapur yang digunakan sebanyak $30 \mathrm{~g}$ dalam sekali proses peleburan. Terak timah tersebut-dianalisis menggunakan alat X-Ray Fluorescence (XRF) untuk mengetahui komposisi kimianya lalu dilakukan pengujian X-Ray Diffraction (XRD) untuk mengetahui senyawa dalam terak timah, serta mikroskop optik untuk melihat perubahan fasa.

\section{Analisis X-Ray Fluorescence (XRF)}

Pada penelitian ini, dilakukan variasi waktu proses dan rasio reduktor. Variasi waktu proses yang digunakan adalah 20, 30, 40, 50, dan 60 menit. Variasi rasio reduktor yang digunakan adalah $1: 5,1: 7,1: 10,1: 13$, dan 1 : 15 (terak timah : grafit). Percontoh hasil reduksi dan peleburan masing-masing variasi waktu proses dan variasi rasio reduktor dipisahkan antara logam dan terak, kemudian ditimbang. Logam dan terak dianalisis dengan X-Ray Fluorescence (XRF) PANalytical Epsilon $3^{\mathrm{XLE}}$ untuk mengetahui perubahan komposisi kimia seiring dengan bertambahnya waktu proses dan rasio reduktor. Sebelum percontoh dianalisis, dilakukan preparasi terlebih dahulu dengan cara dihaluskan menggunakan mortar dan diayak menggunakan ayakan ukuran mesh 325 .

\section{Analisis X-Ray Diffraction (XRD)}

Karakterisasi logam dan terak menggunakan $X$ Ray Diffraction (XRD) PANalytical $\mathrm{X}^{\prime} \mathrm{Pert}^{3}$ Powder dilakukan dengan sinar-X dari $\mathrm{Cu}-\mathrm{K} \alpha$ dengan panjang gelombang $1,541874 \AA$ dan sudut $2 \theta$ antara $10-80^{\circ}$. Hasil karakterisasi XRD akan menghasilkan puncak-puncakPuncak yang tinggi merupakan fasa kristal, sedangkan yang melebar merupakan fasa amorf. Karakterisasi XRD dilakukan pada percontoh logam dan terak hasil peleburan. Hasil karakterisasi XRD kemudian dianalisis menggunakan program High Score Plus.

\section{Uji Proksimat}

Uji proksimat adalah uji yang sangat penting untuk menentukan kadar air (moisture), abu (ash), zat terbang (volatile matter) dan karbon tetap (fixed carbon) dari grafit. Hasil uji proksimat grafit memiliki kadar karbon tetap yaitu $64,23 \%$. Dilakukan tiga uji proksimat, yaitu analisis kadar air total (SNI 13-3761994), kadar zat terbang/KZT (SNI 13-39991995) dan kadar abu (SNI 3478 : 2010).

\section{Analisis Mikroskop Metalurgi}

Analisis mikroskop metalurgi dilakukan untuk melihat stuktur mikro logam dan terak hasil peleburan dengan kadar titanium tertinggi. Analisis ini dilakukan dengan cara mengamati permukaan logam dan terak yang sebelumnya telah dipreparasi secara mounting menggunakan resin dan hardener, lalu dipoles hingga permukaannya rata.

\section{Variasi Waktu Proses}

1. Menyiapkan terak timah sebanyak $500 \mathrm{~g}$, grafit $150 \mathrm{~g}$ dan batu kapur $30 \mathrm{~g}$ berdasarkan stoikiometri dengan ukuran partikel 200 mesh.

2. Melakukan reduksi dan peleburan menggunakan tungku busur listrik dengan variasi waktu 20, 30, 40, 50 dan 60 menit.

3. Proses peleburan dilakukan pada temperatur $1600^{\circ} \mathrm{C}$ berdasarkan diagram Ellingham.

4. Percontoh didinginkan pada suhu ruang.

5. Memisahkan percontoh logam dari terak.

6. Menimbang percontoh yang telah dilebur antara lain: logam dan terak.

7. Analisis hasil peleburan. 


\section{Variasi Rasio Reduktor}

1. Setelah didapat waktu optimum, selanjutnya dilakukan variasi rasio grafit.

2. Menyiapkan terak timah $500 \mathrm{~g}$, batu kapur $30 \mathrm{~g}$ dan variasi reduktor grafit yaitu 1:5, 1:7 1:10, 1:13, dan 1:15 (terak : grafit).

3. Melakukan peleburan menggunakan tungku busur listrik dengan waktu optimum yang diperoleh.

4. Proses peleburan dilakukan pada temperatur $1600^{\circ} \mathrm{C}$.

5. Percontoh didinginkan pada suhu ruang.

6. Memisahkan percontoh logam dari terak

7. Menimbang percontoh yang telah dilebur antara lain : logam dan terak.

8. Analisis hasil peleburan.

\section{HASIL DAN PEMBAHASAN}

\section{Karakterisasi Terak Timah}

Berdasarkan hasil analisis XRF, terdapat beberapa logam yang terkandung dalam terak timah. Komposisi kimia terak timah dapat dilihat pada Tabel 1.

Tabel 1. Komposisi kimia terak timah (\%wt)

\begin{tabular}{cc}
\hline Unsur & Kadar $(\%)$ \\
\hline $\mathrm{Na}$ & 0,554 \\
$\mathrm{Mg}$ & 0,523 \\
$\mathrm{Al}$ & 5,03 \\
$\mathrm{P}$ & 1,06 \\
$\mathrm{~K}$ & 0,335 \\
$\mathrm{Ca}$ & 12,44 \\
$\mathrm{Sc}$ & 0,032 \\
$\mathrm{Ti}$ & 5,71 \\
$\mathrm{~V}$ & 0,0352 \\
$\mathrm{Cr}$ & 0,140 \\
$\mathrm{Mn}$ & 0,407 \\
$\mathrm{Fe}$ & 10,51 \\
$\mathrm{Y}$ & 0,827 \\
$\mathrm{Zr}$ & 5,33 \\
$\mathrm{Nb}$ & 0,646 \\
$\mathrm{Sn}$ & 1,36 \\
$\mathrm{Ba}$ & 0,036 \\
$\mathrm{La}$ & 0,309 \\
$\mathrm{Ce}$ & 1,33 \\
$\mathrm{Nd}$ & 0,55 \\
$\mathrm{Gd}$ & 0,092 \\
$\mathrm{Dy}$ & 0,091 \\
$\mathrm{Er}$ & 0,071 \\
$\mathrm{Yb}$ & 0,067 \\
$\mathrm{Hf}$ & 0,090 \\
\hline
\end{tabular}

\begin{tabular}{cc}
\hline Unsur & Kadar $(\%)$ \\
\hline Ta & 0,448 \\
W & 0,864 \\
Th & 0,410 \\
U & 0,045 \\
Si & 12,38 \\
\hline
\end{tabular}

Dari hasil analisis XRF kadar titanium dalam terak timah cukup rendah yaitu 5,71\% bila dibandingkan dengan kadar kalsium, silikon, dan besi.

\section{Uji Proksimat Grafit}

Grafit merupakan sumber karbon yang bertindak sebagai reduktor yang mereduksi oksida logam menjadi logam murni yaitu mereduksi titanium oksida menjadi titanium. Hasil uji proksimat grafit yang digunakan pada penelitian ini dapat dilihat pada Tabel 2.

Table 2. Hasil uji proksimat grafit

\begin{tabular}{lc}
\hline \multicolumn{1}{c}{ Parameter } & Hasil (\%wt) \\
\hline Kadar air (moisture) & 9,63 \\
Kadar abu (ash) & 13,92 \\
Kadar zat terbang (volatile matter) & 12,22 \\
Kadar karbon tetap (fixed carbon) & 64,23 \\
\hline
\end{tabular}

\section{Analisis XRF Logam dan Terak dari Hasil Varisasi Waktu Proses}

Hasil analisis XRF logam dan terak untuk variasi waktu proses, 20, 30, 40, 50 dan 60 menit dengan rasio reduktor 1:15 ditunjukkan pada Gambar 1 dan 2. Komposisi kimia logam dan terak memiliki persentase berbeda-beda seiring dengan bertambahnya waktu proses. Penambahan batu kapur pada proses reduksi dan peleburan membantu mengikat pengotor, sehingga terpisah dari logam dan membentuk terak. Gambar 1 menunjukkan hubungan antara waktu proses dan perubahan kadar logam hasil peleburan.

Hasil analisis XRF menunjukkan bahwa pengaruh waktu proses khususnya terhadap kadar titanium pada produk logam mengalami perubahan dengan variasi waktu proses dari 20 sampai dengan 60 menit. Perubahan tersebut ditunjukkan pada pada Gambar 2. 


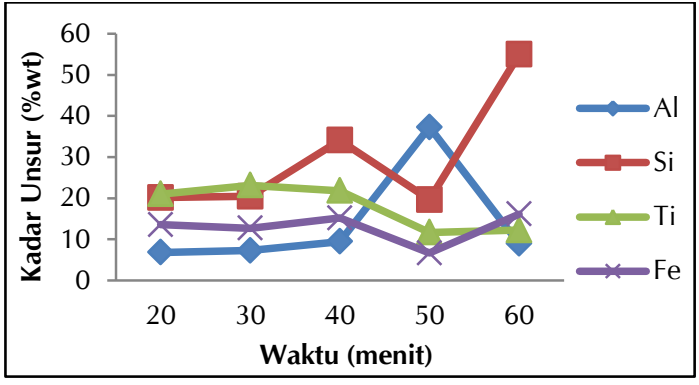

Gambar 1. Pengaruh waktu proses terhadap komposisi kimia produk logam

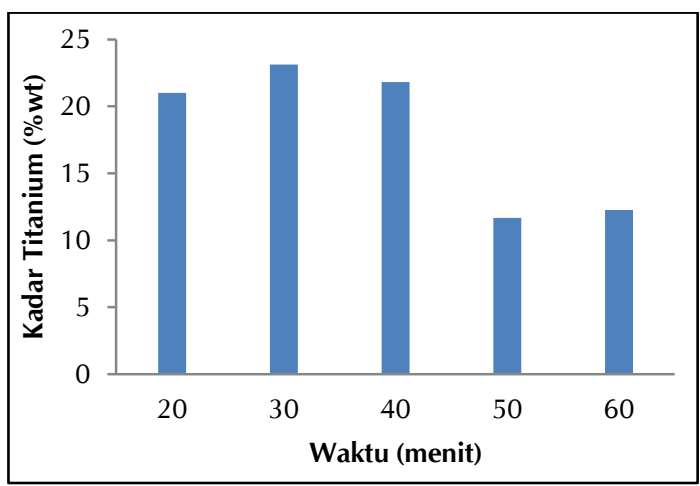

Gambar 2. Pengaruh waktu proses terhadap kadar titanium produk logam

Berdasarkan grafik pada Gambar 2 dapat dilihat kadar titanium pada produk logam mengalami peningkatan dari waktu proses 20 sampai 30 menit kemudian mengalami penurunan untuk waktu proses 40 sampai dengan 60 menit. Peningkatan dan penurunan ini menunjukkan bahwa proses reduksi $\mathrm{Ti}$ dipengaruhi waktu. Berdasarkan diagram Ellingham, posisi $\mathrm{Ti}$ berada di bawah $\mathrm{Si}, \mathrm{Fe}$, tetapi berada di atas Al (Upadhyaya dan Dube, 1977), sehingga berdasarkan posisi tersebut Ti akan tereduksi setelah Fe dan Si tereduksi lebih dahulu. Kemudian setelah Ti tereduksi, Al yang tereduksi. Karena proses reduksi yang terjadi cukup kompleks perlu diketahui waktu optimal. Dalam hal ini waktu optimal proses reduksi dan peleburan $\mathrm{Ti}$ agar diperoleh kadar yang tinggi yaitu waktu proses selama 30 menit dengan kadar Ti yang tinggi dan kadar unsur lainnya serendah mungkin pada produk logam. Keberhasilan proses peleburan ini selain dilihat dari kadar Ti pada produk tetapi juga dilihat dari persen ektraksi Ti. Persen ekstraksi titanium hasil percobaan ditampilkan pada Gambar 3.

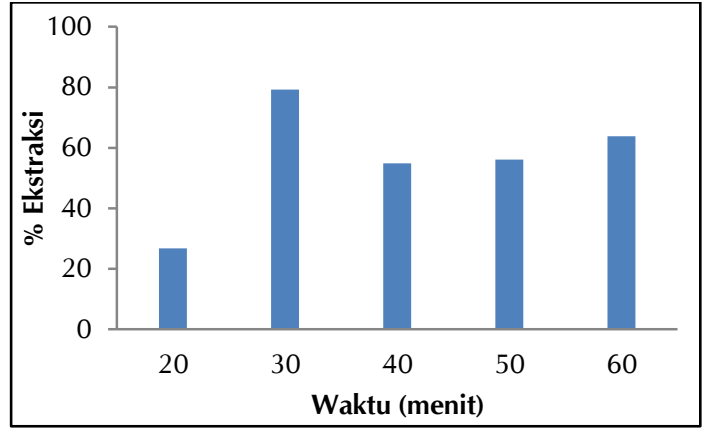

Gambar 3. Pengaruh waktu proses terhadap persen ekstraksi titanium pada produk logam

Grafik pada Gambar 3 menunjukkan pengaruh waktu proses terhadap persen ekstraksi titanium. Berdasarkan percobaan waktu optimum untuk mendapatkan hasil ekstraksi titanium tertinggi yaitu pada waktu proses 30 menit yang menghasilkan persen ekstraksi titanium sebesar 79,21\%.

\section{Analisis XRF Logam dan Terak dari Hasil Varisasi Rasio Reduktor}

Hasil analisis XRF logam dan terak dari variasi rasio reduktor $1: 5,1: 7,1: 10,1: 13$, dan 1:15 dengan waktu peleburan 30 menit ditunjukkan pada Gambar 4. Hasil menunjukkan komposisi kimia dari logam dan terak memiliki persentase yang berbeda-beda berdasarkan rasio reduktor.

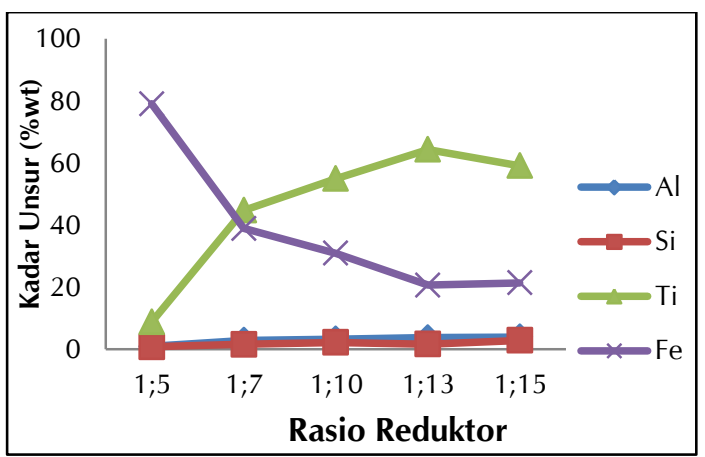

Gambar 4. Pengaruh rasio reduktor terhadap komposisi kimia pada produk logam

Berdasarkan Gambar 4 terlihat bahwa kadar $\mathrm{Ti}$ pada produk logam semakin meningkat seiring bertambahnya rasio reduktor. Hal ini menunjukkan semakin meningkatnya rasio reduktor maka ketersediaan karbon dan 
$\mathrm{P}_{\mathrm{CO}} / \mathrm{P}_{\mathrm{CO} 2}$ tetap terjaga sehingga proses reduksi Ti dapat berjalan terus yang pada akhirnya kadar Ti pada produk logam semakin tinggi.

Sama seperti pengaruh waktu proses, pengaruh rasio reduktor juga dilihat pengaruhnya terhadap persen ektraksi Ti. Pengaruh rasio reduktor terhadap persen ekstraksi titanium hasil percobaan ditampilkan pada Gambar 5.

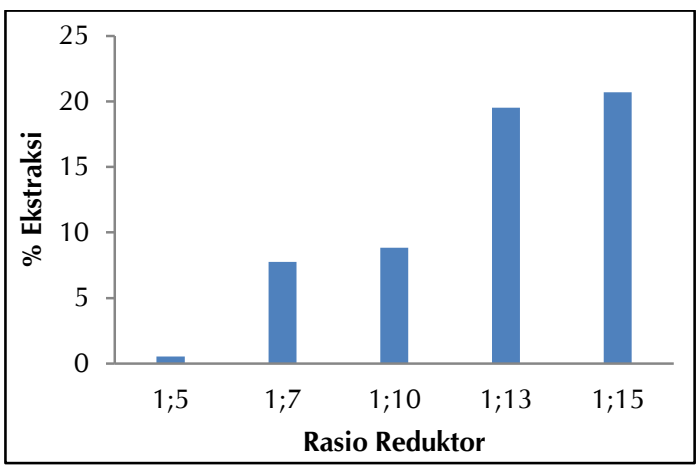

Gambar 5. Pengaruh rasio reduktor terhadap persen ekstraksi titanium pada produk logam

Gambar 5 menunjukkan persen ekstraksi titanium yang tertinggi yaitu sebesar $20,70 \%$ dan rasio reduktor yang digunakan 1:15. Peningkatan persen ekstraksi titanium disebabkan oleh bertambahnya jumlah ketersediaan karbon yang berfungsi sebagai pereduksi titanium oksida menjadi titanium. Berdasarkan diagram Ellingham, karbon akan terlebih dahulu mereduksi logam lain yang lebih mudah tereduksi misalnya seng (Uphadaya, 1977). Oleh karena itu, jika jumlah grafit sebagai pasokan karbon ditambahkan semakin banyak, dapat menyebabkan penurunan persen ekstraksi titanium.

\section{Analisis Mikroskop Metalurgi}

Hasil analisis mikroskop metalurgi dapat dilihat pada Gambar 6. Berdasarkan Gambar 6 (a) dan (b) dapat dilihat perbandingan antara logam dan terak, pada logam, terdapat warna terang yang menunjukan terdapatnya logam lebih banyak bila dibandingkan dengan yang terdapat pada terak. Pada terak warna terang hanya sedikit dan lebih dominan warna hitam yang menunjukkan pengotor.

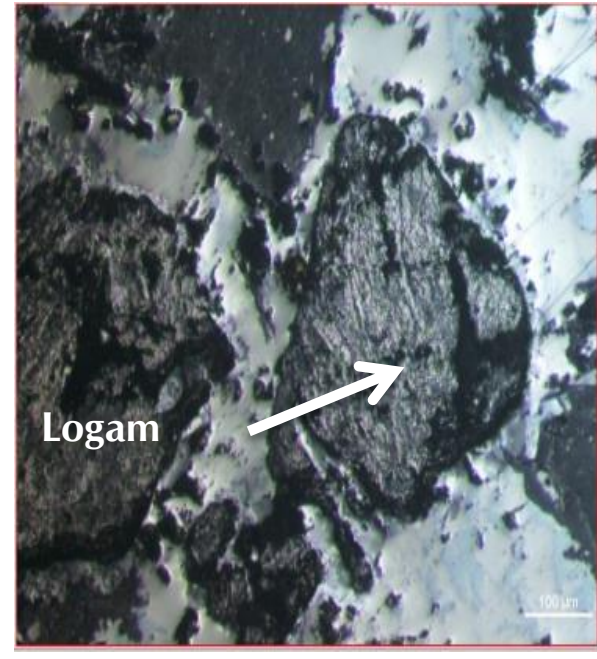

(a)

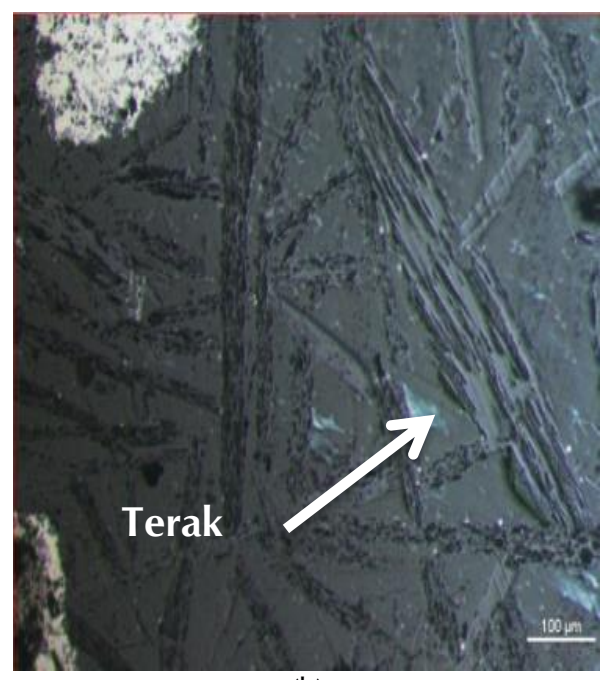

(b)

Gambar 6. Analisis mikroskop metalurgi logam dan terak hasil peleburan (a) logam perbesaran 10x (b) terak perbesaran $10 \mathrm{x}$

\section{Pengaruh Waktu Proses terhadap Perubahan Fasa}

Percontoh dipreparasi terlebih dahulu sebelum dianalisis XRD dengan cara dihaluskan menggunakam mortar dan diayak ayakan ukuran mesh 325 agar lebih terliberasi. Gambar 7 menunjukkan perubahan fasa titanium pada logam hasil peleburan seiring dengan bertambahnya waktu proses. Pada waktu proses 20 menit, fasa yang terbentuk berupa $\mathrm{Ti}_{0,626} \mathrm{Fe}_{0,233} \quad \mathrm{~V}_{0,141}$. Waktu 30 menit menghasilkan fasa yang terbentuk berupa Tio.95 Cro,05. Waktu proses 40 menit, fasa yang terbentuk adalah $\mathrm{Ti}_{0,89} \mathrm{Zr}_{\mathrm{r}, 11}$. Hasil waktu proses 50 menit membentuk fasa $\mathrm{Ti}_{3} \mathrm{Sn}$. Pada waktu 
proses 60 menit, fasa yang terbentuk berupa $\mathrm{Ti} i, 86 \mathrm{~V}_{1,14}$. Jika dilihat dari perubahan fasa yang terjadi, menunjukkan bahwa variasi waktu berpengaruh terhadap perubahan fasa logam titanium. Perubahan fasa ini sangat berkaitan dengan proses reduksi pada diagram Ellingham.
Diagram Ellingham menunjukkan bahwa $\mathrm{Fe}$ tereduksi terlebih dahulu, lalu $\mathrm{Cr}$ yang dan, selanjutnya Zr, Sn dan V. Berdasarkan hasil tersebut, terdapat kesesuaian dengan fasa titanium yang terbentuk.

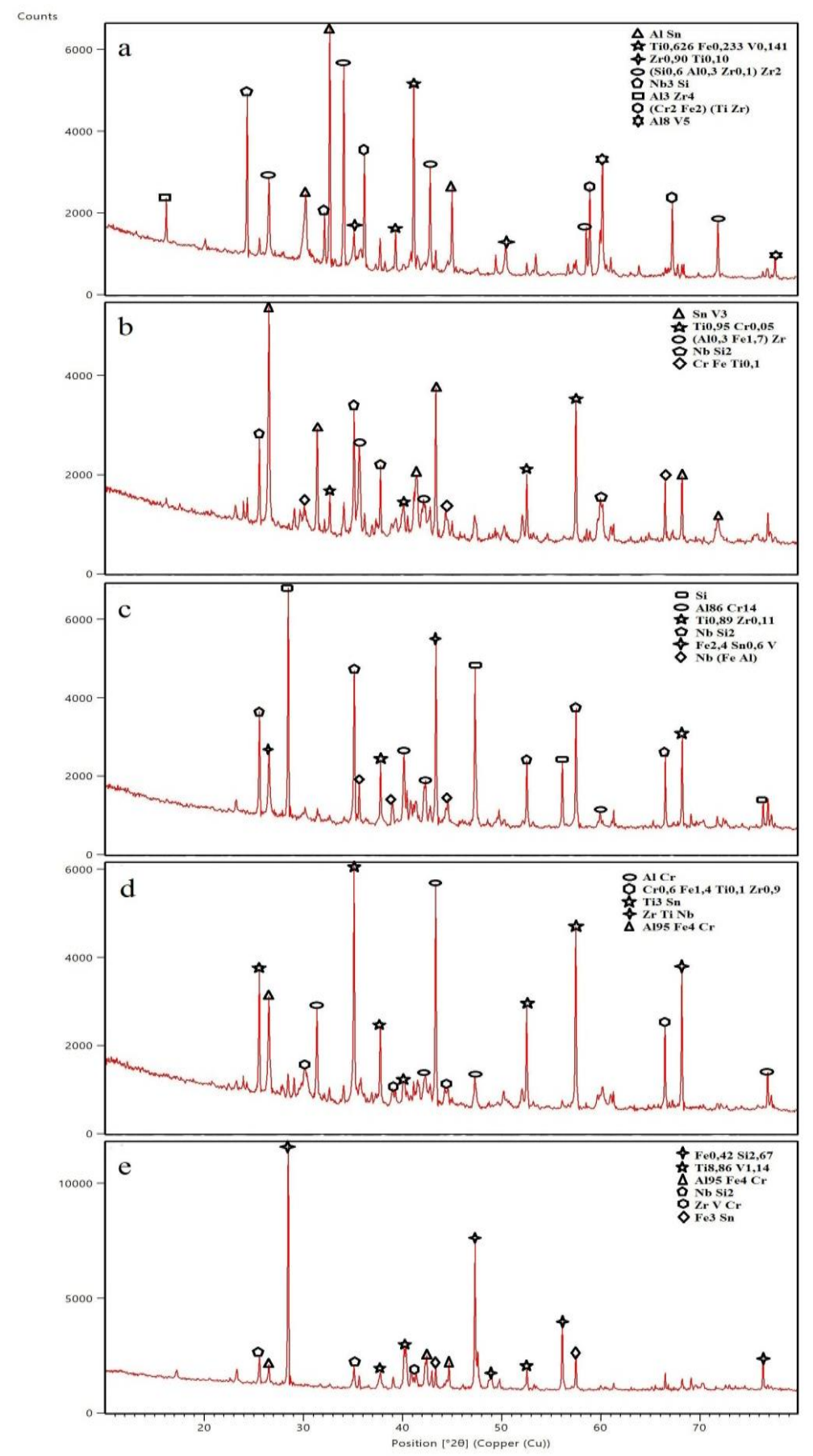

Gambar 7. Difraktogram XRD logam hasil peleburan dengan variasi waktu (a) 20 menit, (b) 30 menit, (c) 40 menit, (d) 50 menit, (e) 60 menit 
Gambar 8 menunjukkan senyawa dominan yang terbentuk pada terak hasil reduksi dan peleburan dengan variasi waktu 20, 30, 40, 50 dan 60 menit berupa senyawa $\mathrm{Al}_{2} \mathrm{O}_{3}$. Semakin betambah waktu proses menyebabkan terjadinya perubahan fasa pada produk logam dan terak yang terbentuk. Semakin bertambahnya waktu proses menyebabkan semakin banyak pengotor yang tereduksi.

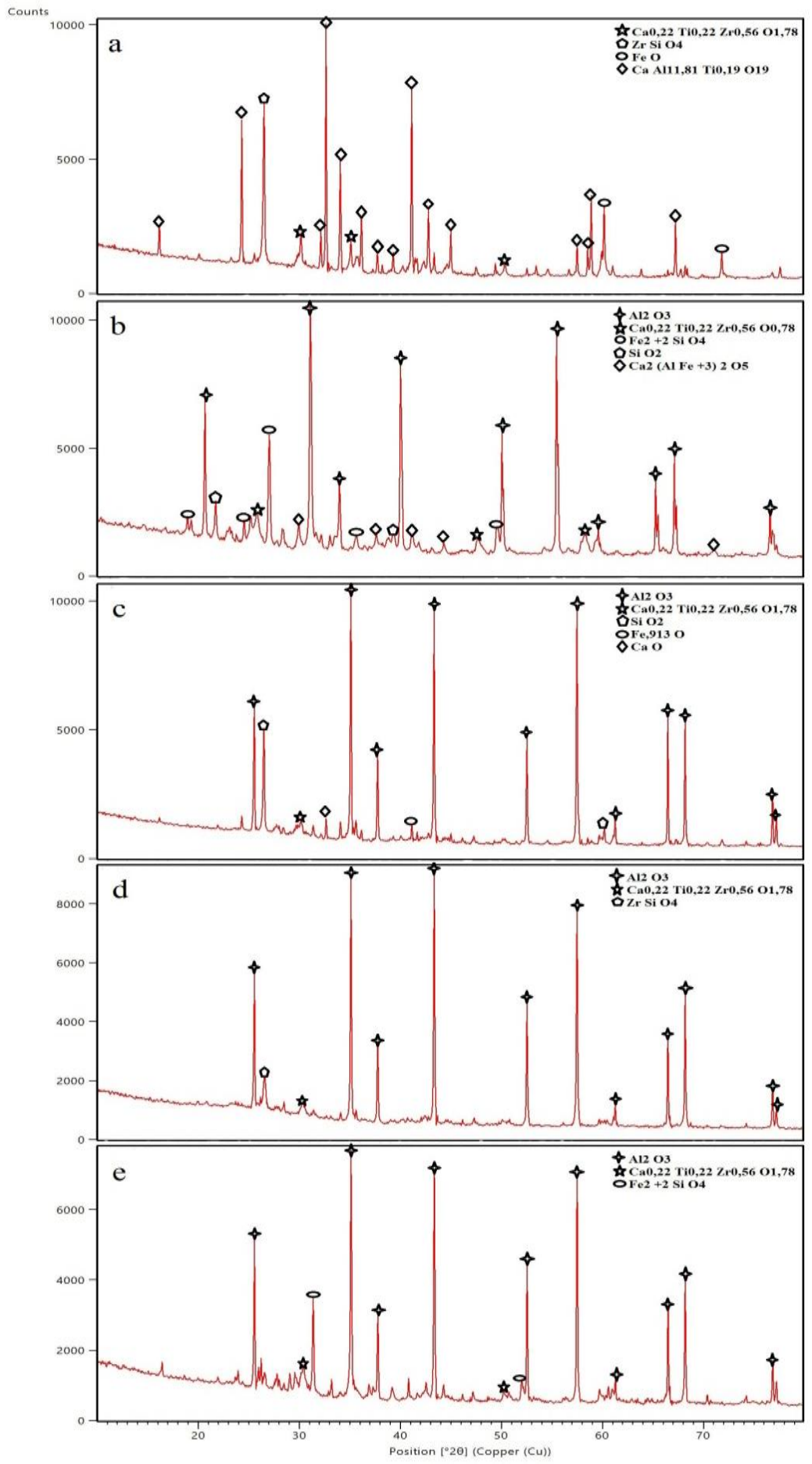

Gambar 8. Difraktogram XRD terak hasil peleburan dengan variasi waktu (a) 20 menit, (b) 30 menit, (c) 40 menit, (d) 50 menit, (e) 60 menit 


\section{Pengaruh Rasio Reduktor terhadap Perubahan Fasa}

Analisis XRD dilakukan pada percontoh hasil peleburan dengan variasi rasio reduktor $1: 5$, 1:7, 1:10, 1:13, dan 1:15. Sebelum dianalisis percontoh dipreparasi terlebih dahulu dengan cara dihaluskan menggunakan mortar dan diayak ayakan ukuran mesh 325 agar lebih terliberasi. Difraktogram XRD menunjukkan fasa-fasa yang terbentuk pada logam dan terak disajikan pada Gambar 9 dan 10.

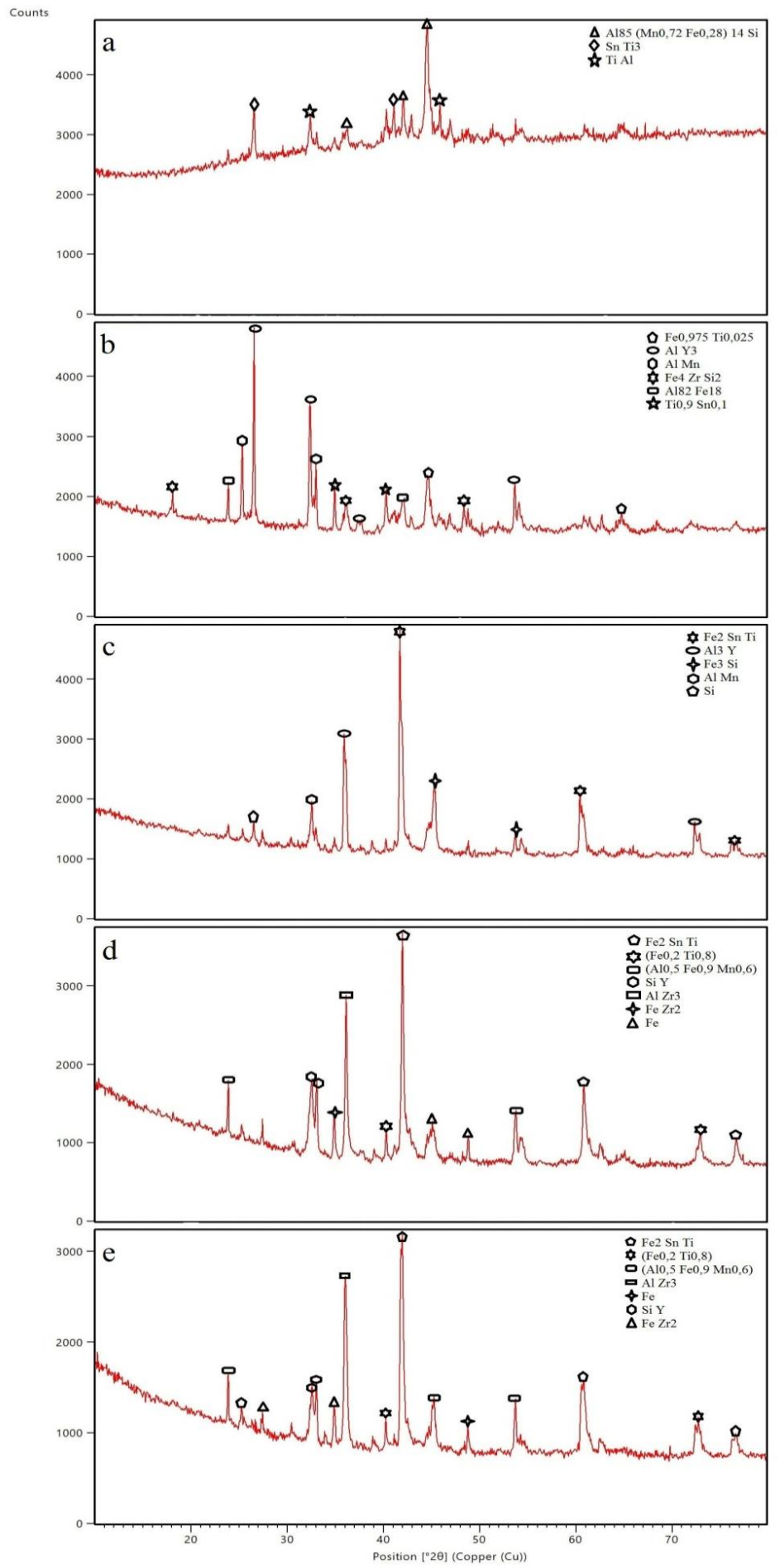

Gambar 9. Difraktogram XRD logam hasil peleburan dengan rasio reduktor (a) 1:5, (b) 1:7, (c) 1:10, (d) 1:13, (e) 1:15 


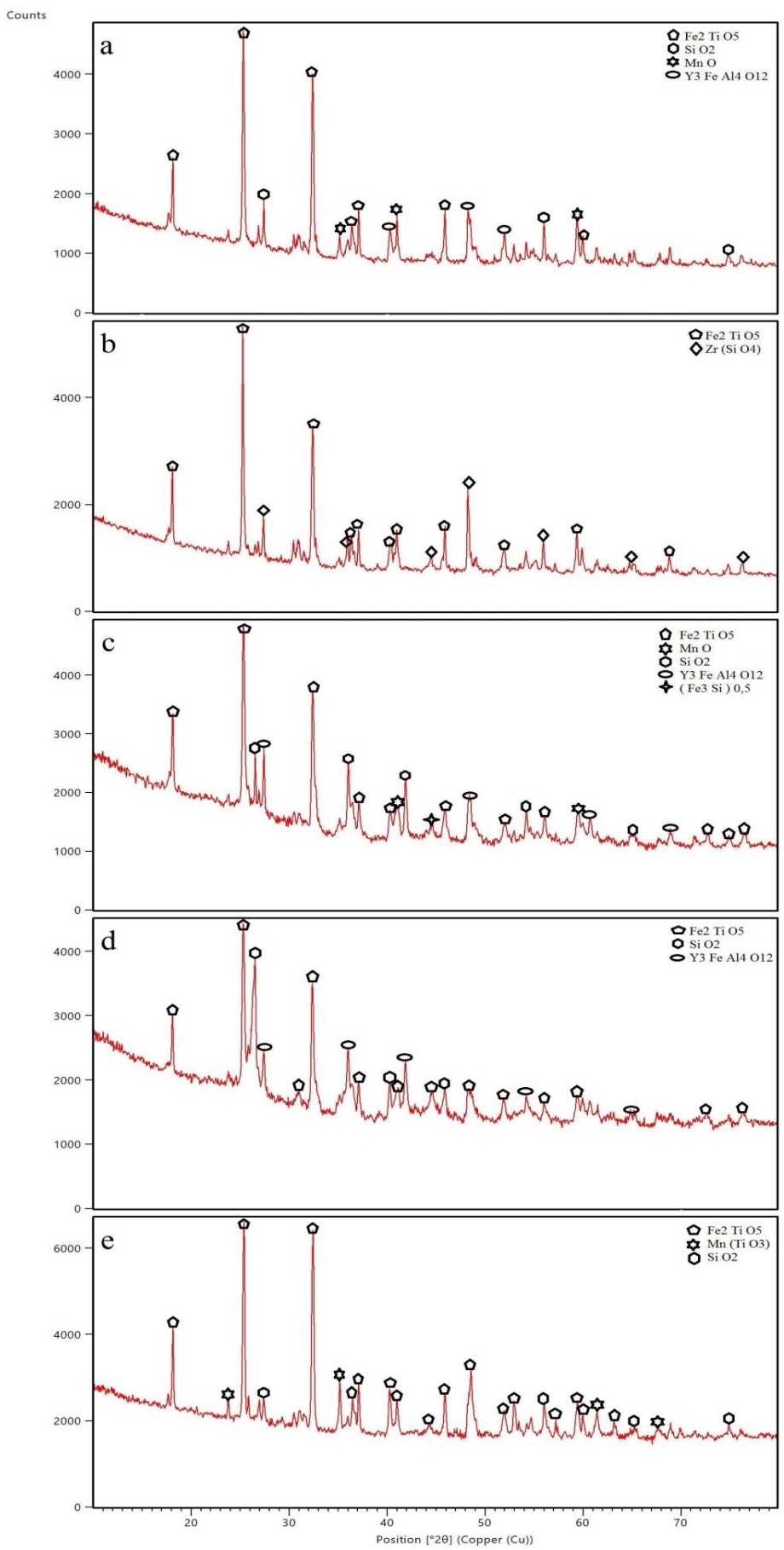

Gambar 10. Difraktogram XRD terak hasil peleburan dengan rasio reduktor (a) $1: 5$, (b) $1: 7$, (c) $1: 10$, (d) $1: 13$, (e) $1: 15$

Gambar 9 adalah hasil peleburan dengan rasio reduktor yang menunjukkan sedikit perubahan fasa tidak terlalu signifikan seiring dengan bertambahnya waktu proses. Pada rasio reduktor 1:5, fasa yang terbentuk berupa $\mathrm{SnTi}_{3}$ sedangkan pada rasio reduktor $1: 7$, fasa yang terbentuk berupa $\mathrm{Fe}_{2} \mathrm{SnTi}$. Rasio reduktor 1:10 membentuk fasa berupa $\mathrm{Fe}_{2} \mathrm{SnTi}$. Pada rasio reduktor 1:13 fasa yang terbentuk berupa $\mathrm{Fe}_{2} \mathrm{SnTi}$ dan pada rasio reduktor 1:15, fasa yang terbentuk berupa $\mathrm{Fe}_{2} \mathrm{SnTi}$. Hasil XRD variasi rasio reduktor menunjukkan hasil bahwa fasa yang terbentuk dominan berupa $\mathrm{Fe}_{2} \mathrm{SnTi}$. 
Gambar 10 menunjukkan senyawa dominan yang terbentuk pada terak hasil peleburan dengan variasi rasio reduktor 1:5, 1:7, 1:10, 1:13, dan 1:15 berupa senyawa $\mathrm{Fe}_{2} \mathrm{TiO}_{5}$. Variasi rasio reduktor tidak menyebabkan perubahan fasa yang signifikan, pada produk logam yaitu $\mathrm{Fe}_{2} \mathrm{SnTi}$ dan pada terak $\mathrm{Fe}_{2} \mathrm{TiO}_{5}$.

\section{KESIMPULAN DAN SARAN}

Produk titanium tertinggi yang dihasilkan adalah $23,11 \%$ pada waktu proses 30 menit. Waktu optimum untuk mendapatkan hasil ekstraksi titanium tertinggi yaitu pada waktu proses 30 menit yang menghasilkan persen ekstraksi titanium sebesar 79,21 \% dengan rasio reduktor 1:15. Peningkatan persen ekstraksi titanium disebabkan oleh bertambahnya jumlah grafit yang digunakan. Grafit bertindak sebagai penyedia karbon yang berfungsi sebagai pereduksi titanium oksida menjadi titanium. Variasi rasio reduktor tidak menyebabkan perubahan fasa yang signifikan, pada produk logam yaitu $\mathrm{Fe}_{2} \mathrm{SnTi}$ dan pada terak $\mathrm{Fe}_{2} \mathrm{TiO}_{5}$. Penelitian selanjutnya disarankan melakukan variasi jenis reduktor lainnya misal menggunakan batubara jenis bituminus

\section{UCAPAN TERIMA KASIH}

Terima kasih kami sampaikan kepada PTBGNBATAN dan PT Timah, Tbk. yang telah menyediakan percontoh terak timah untuk penelitian ini. Kami juga menyampaikan terima kasih kepada BPTM-LIPI yang telah memfasilitasi peralatan dan KEMENRISTEKDIKTI yang telah mendukung pendanaan melalui program INSINAS untuk kegiatan penelitian ini.

\section{DAFTAR PUSTAKA}

Gambogi, J. (2006) "Titanium," in 2006 Minerals Yearbook. US Geological Survey, hal. 78.178.14 .

Mareta, Y. (2011) Magang tentang keselamatan dan kesehatan kerja di unit metalurgi muntok PT Timah (Persero) Tbk Bangka Belitung. Surakarta.

Melita (2015) "Pengaruh penggunaan limbah pengolahan timah (tin terak) sebagai subsitusi parsial agregat halus terhadap kuat tekan dan kuat tarik belah beton," Jurnal Profil, 3(1), hal. 41-51.

Middlemas, S., Fang, Z. Z. dan Fan, P. (2013) "A new method for production of titanium dioxide pigment," Hydrometallurgy, 131132, hal. 107-113.

doi: 10.1016/j.hydromet.2012.11.002.

Nie, X., Dong, L., Bai, C., Chen, D. dan Qiu, G (2006) "Preparation of $\mathrm{Ti}$ by direct electrochemical reduction of solid $\mathrm{TiO} 2$ and its reaction mechanism," Transactions of Nonferrous Metals Society of China, 16, hal. s723-s727.

doi: 10.1016/S1003-6326(06)60288-4.

Permana, S., Soedarsono, J. W., Rustandi, A. dan Maksum, A. (2016) "Other oxides pre-removed from Bangka tin slag to produce a high grade tantalum and niobium oxides concentrate," IOP Conference Series: Materials Science and Engineering, 131, hal. 012006. doi: 10.1088/1757-899X/131/1/012006.

Sulistiyono, E., Firdiyono, F. dan Suharyanto, A. (2014) "Proses peralutan asam sulfat dan asam klorida terhadap hasil reduksi terak timah," Majalah Metalurgi, 29(3), hal. 197-204.

Supriyatna, Y. I. dan Shofie, A. (2013) "Uji performa tungku busur listrik satu fase skala laboratorium dalam proses pembuatan ferromangan," in Prosiding Semirata FMIPA Universitas Lampung. Lampung: Semirata FMIPA Universitas Lampung, hal. 527-530.

Tangstad, M. dan Olsen, S. E. (1995) "The ferromanganese process material and energy balance," in Tuset, J. K., Tveit, H., dan Page, I. G. (ed.) INFACON 7. Trondheim: The Norwegian Ferroalloy Research Organization, hal. 621-630.

Upadhyaya, G. S. dan Dube, R. K. (1977) Problems in metallurgical thermodynamics and kinetics. Elsevier. doi: 10.1016/C2013-0-02782-X.

Xue, T., Wang, L., Qi, T., Chu, J., Qu, J. dan Liu, C. (2009) "Decomposition kinetics of titanium slag in sodium hydroxide system," Hydrometallurgy, 95(1-2), hal. 22-27.

doi: 10.1016/j.hydromet.2008.04.004.

Yuliana, H. S. (2017) "Analisis dampak pertambangan timah rakyat terhadap bencana banjir: Studi pada Kota Pangkalpinang Provinsi Kepulauan Bangka Belitung tahun 2016," Jurnal Prodi Manajemen Bencana, 3(1), hal. 57-73. 
